\title{
Photosynthate Allocation and Productivity of Latex Vessels in Hevea brasiliensis
}

\author{
J.-M. Eschbach, J. TupÝ* and R. Lacrotte \\ Institut des Recherches sur le Caoutchouc (I.R.C.A.), \\ B.P. 1536 Ol-Abidjan, Ivory Coast
}

\begin{abstract}
Manipulations of production systems in rubber tree which were intended to improve sucrose translocation in tapped bark resulted in an increase of latex sucrose and of látex production and reduced the incidence of nonyielding laticiferous tissue. This was achieved by shortening the tapping cut from full to half spiral, by changing the descending direction into an ascending mode of tapping or by anmual change-over of tapping panel allowing for a longer time the regeneration of bark removed above the location of the cut. The increase of latex yield did not result in a significant decrease in the growth of trees over a period of three years.

Clonal differences in nonyielding bark appeared to be related to differences in sucrose depletion by tapping. In clone PB 235 which exhibited low latex sucrose, a reduction of tapping frequency resulted in an increase in sucrose level and in a decrease of bark "dryness" tending to an increase in total yield.

The tapping manipulations examined did not affect latex flow characteristics such as the plugging index of latex vessels and the bursting index of lutoids. The results stress the importance of photosynthate allocation for the physiology of laticiferous system productivity and indicate the possibilities of improving assimilate economy in rubber trees.
\end{abstract}

Hevea latex, the rubber containing cytosol of latex vessels (ARCHer et al. 1963. Dickenson 1965) is commercially extracted by controlled cutting of secondary phloem tissue of the trunk, known as tapping, which is practised at regular time intervals, normally twice a week. The yielding peculiarities of the rubber tree thus consist in that the economical product is continuously removed from the site of its formation and its analysis makes it possible to examine metabolic factors of productivity.

Saccharides are supplied to latex vessels as sucrose (TUPÝ and RESING 1968, TUPÝ 1985) and its utilization in latex metabolism is limited by the activity of latex invertase which in turn is strongly $\mathrm{pH}$ dependent (TUPÝ 1969). The tapping results in a decrease of sucrose content in the latex (Bealing and Chua 1972, Tupý 1973a) which indicates that the sucrose exported and utilized in latex metabolism is not fully replaced by translocated sucrose. The sucrose depletion is genotype dependent (TUPÝ 1973b, Low

Received October 7, 1985; accepted February 20, 1986

* On mission as expert of the International Atomic Energy Agency.l

Permanent address: Institute of Experimontal Botany, Czechoslovak Academy of Sciences, Flemingovo nám. 2, CS-16000 Praha 6, Czechoslovakia. 
1978, Eschbach et al. 1984) and increases with the intensity of exploitation system applied (Bealing and CHUA 1972, TUPÝ $1973 \mathrm{a}, 1985$, Low and GOMEz 1982). Saccharides depletion can negatively affect yield directly through the link of latex formation and flow to saccharides catabolism, and indirectly by an increase of nonyielding tapping cuts (TUPÝ 1985).

An improvement of saccharides status of latex vessels could thus increase their productivity. This was achieved by manipulating production systems predicted to improve sucrose translocation and by reducing tapping frequency at high sucrose depletion by tapping. The physiological nature of enhanced yield was examined by analysis of various latex characteristics.

\section{MATERIAL AND METHODS}

The experimental trees of Hevea brasiliensis (Kunth) MüLL. ARg. were grown in regular plantations of the Rubber Research Institute of the Ivory Coast at a density of 510 trees per ha. The tapping cut was applied as a full spiral (S) or a half-spiral (1/2 S). The stimulation by Ethrel was normally generated by applying palm oil containing a preparation of $2.5 \%$ of 2 -chloroethylphosphonic acid on a $2 \mathrm{~cm}$ band of scraped bark at the tapping cut. The details are given in descriptions of individual experiments.

The latex was collected from healthy trees of representative girth and yield and analysed as described by Eschвach et al. (1984). Most results refer to the latex obtained 5 to 35 min after the beginning of flow. The exceptions are specified in the text. Latex for analysis was collected from tapping just before a new bark treatment with Ethrel. The following parameters were measured: total solid content, sucrose, thiols (R-SH), $\mathrm{Mg}^{2+}, \mathrm{Pi}, \mathrm{pH}$, redox potential (RP), bursting index of lutoids (BI) and plugging index of latex vessels (PI). The growth was estimated by measuring the circumference of the trunk at a height of $2.3 \mathrm{~m}$. The incidence of bark dryness was followed by recording the unproductive length of the tapping cut.

\section{RESULTS}

\section{Effects of Bark Removal by Tapping}

The long term effects of bark reduction by the process of tapping were investigated in a three year assay on the clone GT 1 comparing $S$ and $1 / 2 \mathrm{~S}$ downward tapping and $1 / 2 \mathrm{~S}$ tapping in ascending direction in which the panel of consumed bark remains below the cut.

The growth of trees as measured by girth increment was independent of the length of the eut but was slightly reduced by the ascending mode of tapping (Fig. 1). The difference was, however, statistically not significant. Total rubber yield was significantly the lowest in the case of S cut and the highest with the upward tapping, amounting to $142 \%$ and $168 \%$ with respect to the descending systems 2 or 3 , respectively. As concerned the incidence of dry tapping cuts, that is cuts which partially or completely ceased to yield latex, with the $S$ tapping as much as $48 \%$ of the total length of the incisions became unproductive, while in the case of downward and upward half-spirals the cut length yielding no latex made only 9.7 and $1.3 \%$, respectively.

The removal of bark by tapping reduces downward sucrose translocation to latex producing vessels and this effect increases with the increase of the 
surface of the consumed bark above the tapping cut (TUPÝ 1985). The bark after tapping is renewed by cambial activity and is ready to be tapped again in about 10 to 12 years. As expected, the time of bark renewal above the cut appeared to be of importance for latex production and some physiological latex characteristics. In the respective experiment, two downward $1 / 2 \mathrm{~S}$.

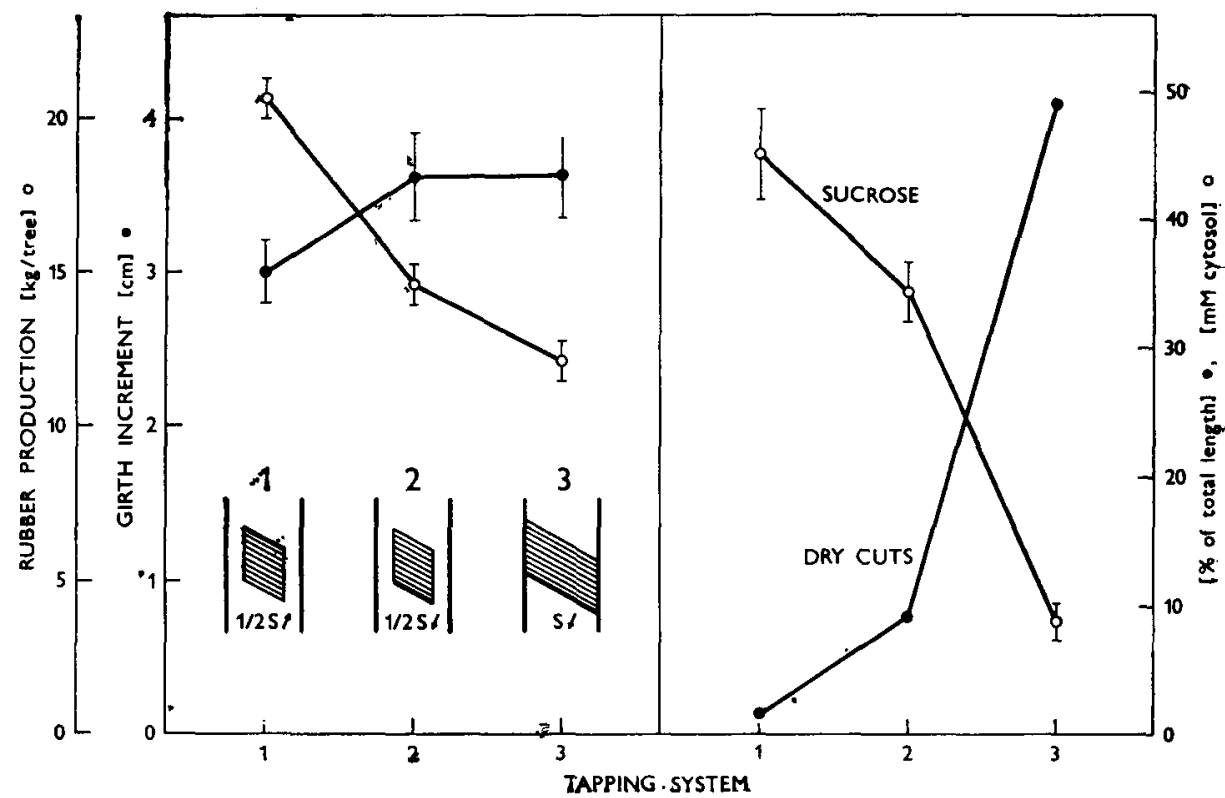

Fig. 1. Effect of the tapping system on saccharides feeding and productivity of latex vessels. The experiment started on trees of GT 1 clone 15 years old which have already been tapped for 5 years in $\mathrm{S}$ twice a week and for 5 years in $1 / 2 \mathrm{~S}$ at the same frequency with 4 stimulations by Ethrel per year. Data are means \pm s.e. of 33 trees. Results on production and growth cover a period of 3 years. Sucrose content in the latex and incidence of bark dryness were estimated in November of the third year. Differences between the treatments are significant in all parameters except girth increment. The dashed area indicates the regenerating bark after previous tappings and the arrows correspond to the direction in which the bark is removed.

systems were compared differing in the time of changing the tapping cut. position from one to the opposite side of the trunk (Fig. 2). Before the trial, the trees were tapped in $\mathrm{S}$ for three years. During the period of the experiment, the replacing of the tapping panel every year (treatment $B$ ) gave higher latex yields than continuous tapping on the same half of the trunk (treatment A). In the fourth year, when the trees exploited in the latter manner became tapped on the opposite side below the bark that was renewing already for four years, the production greatly increased and the latex obtained differed from the latex of trees A, tapped below only two years old regenerating bark, in several properties (Table 1). It contained more sucrose, more reduced thiols and $\mathrm{Mg}^{2+}$ and exhibited a higher redox potential. On the other hand, latex $\mathrm{pH}$, total solids and Pi content, the bursting index of latex lutoids and the plugging index did not differ significantly. The incidence of dryness in tapped bark was significantly lower in trees with the older renewing. bark above the cut. 


\section{Clonal Differences in Latex Sucrose and Bark Dryness}

In a comparative clonal field under a normal management practice, significant difference in the incidence of dry cuts was registered in the 4th year of tapping. The clones showed decreasing proportion of nonyielding cut length from 21.4 to $4.8 \%$ in the order PB 235, GT 1, AVROS 2037, RRIM 600 , PB 217. Exactly in the same order, an increase of the level of sucrose in latex cytosol from 5.2 to $33.7 \mathrm{mM}$ was found (Table 2).

\section{Effect of Tapping Frequency}

In the clone PB 235 exhibiting low latex sucrose and high incidence of bark dryness, a $25 \%$ reduction of tapping frequency in combination with a milder but more frequent bark treatment with Ethrel resulted in an almost $50 \%$ rise in latex sucrose, in a significant diminution of dry cut appearance and in a nearly $40 \%$ increase of latex production per tapping (Table 3 ). In addition to higher sucrose, the latex of less frequently tapped trees exhibited higher $\mathrm{pH}$ with respect to the control. On the other hand, no differences were found in dry rubber content, in the level of reduced thiols, in redox potential, in the bursting index of lutoids and in the index of plugging. Within a 3 years' experiment period, the girth increment was not affected by the change of exploitation.

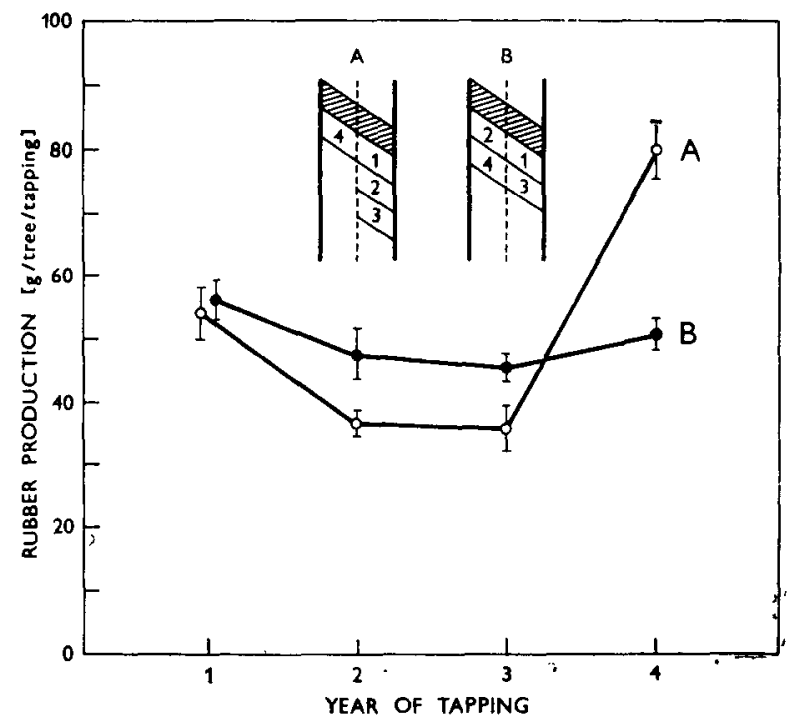

Fig. 2. Effect of change-over of tapping panel on rubber production. Clone GT 1 planted in 1966, brought into tapping in 1972 and tapped from 1977 to 1981 in $\mathrm{S}$ twice a week. During the next 4 years $(1,2,3,4)$, the cut was in $1 / 2 \mathrm{~S}$ and its position on the trunk changed as illustrated. The trees were stimulated 4 times per year by application of $2 \mathrm{~g}$ of Ethrel at $5 \%$ concentration of the active compound on a $2 \mathrm{~cm}$ wide band of scraped bark below the cut. Each treatment included 4 plots per $1632 \mathrm{~m}^{2}$ and 100 trees set up in a 6.25 ha field. The production was measured per plot and the values are means \pm s.e. The statistical treatment showed significant differences in the 2nd and 4th years of the experiment. The dashed area corresponds to the panel of bark removed during the last years of tapping before the experiment and the areas with the numbers indicate bark removal during the subsequent 4 years. 
TABLE 1

Effect of the age of regenerating bark above the tapping cut on phy'siology of latex production. Results obtained towards the end of the fourth year of tapping in the experiment shown in Fig. 2. Each value is a mean of four tree plots. Data on rubber yield are means of 8 tappings before the date of latex collection for anelysis (10 November 1984). The bark regeneration above the tapping cuts of the systems A and B was 4 and 2 years old, respectively. For explanation of RP, BI, PI see Material and Methods

\begin{tabular}{|c|c|c|c|c|c|c|c|c|c|c|c|c|}
\hline \multirow{2}{*}{\multicolumn{2}{|c|}{$\begin{array}{c}\text { Tapping } \\
\text { system }\end{array}$}} & \multirow{2}{*}{$\begin{array}{c}\text { Produc- } \\
\text { tion } \\
{[\mathrm{g} / \text { tree }]}\end{array}$} & \multirow{2}{*}{$\begin{array}{l}\text { Dry cuts } \\
{[\% \text { of }} \\
\text { total] }\end{array}$} & \multicolumn{9}{|c|}{ Latax analysis } \\
\hline & & & & Total & Suc- & R-SH & $\mathrm{Mg}_{2+}$ & $\mathrm{Pi}$ & $\mathrm{pH}$ & $\mathrm{RP}$ & BI & PI \\
\hline \multirow[t]{2}{*}{$A$} & $\overline{\mathbf{x}}$ & 85 & 36 & 43.5 & 45.6 & 0.66 & 12.9 & 14.9 & 6.81 & -7.0 & 19.1 & 18.2 \\
\hline & $\mathrm{s} . \theta$ & 4.7 & 3.1 & 2.4 & 5.6 & 0.02 & 1.0 & 1.5 & 0.07 & 1.1 & 1.5 & 2.0 \\
\hline \multirow[t]{2}{*}{$\mathbf{B}$} & $\overline{\mathbf{x}}$ & 51 & 51 & 43.7 & 28.9 & 0.40 & 8.8 & 12.3 & 6.74 & -4.2 & 19.9 & 18.0 \\
\hline & s.e. & 3.4 & 5.7 & 0.9 & 2.7 & 0.05 & 1.2 & 0.9 & 0.07 & 0.5 & 2.0 & 1.2 \\
\hline \multicolumn{2}{|c|}{$\begin{array}{l}\text { Significance } \\
\text { of differences } \\
\text { at } P< \\
<0.05 \%\end{array}$} & $\mathbf{A}>\mathbf{B}$ & $B>A$ & NS & $\mathbf{A}>\mathbf{B}$ & $A>B$ & $\mathbf{A}>\mathbf{B}$ & NS & NS & $\mathrm{A}>\mathrm{B}$ & NS & NS \\
\hline
\end{tabular}

\section{DISCUSSION}

Earlier studies on the saccharides status of latex vessels indicated that sucrose availability for metabolic activities implicated in latex flow and production is an important limiting factor of latex yield (TUPÝ 1973b). Latex tapping reduces growth indicating that at least part of translocated sugars used for latex production is to the detriment of growth activities which can greatly reduce potential future productivity (TEMPLETON 1969). The tapping also results in a depletion of the storage saccharide pool (CHONG 1981), the mobilization of which can temporarily compensate disproportions between photosynthate consumption and availability from photosynthetic sources.

\section{TABLE 2}

Clonal differences in the incidence of bark dryness and the level of latex sucrose. - Comparative clonal trial planted in 1974 and tapped in $1 / 2 \mathrm{~S}$ twice a week with four Ethrel applications per year on $2 \mathrm{~cm}$ of scrapped bark below the tapping cut at $5 \%$ concentration of the active compound. For sucrose determination total latex was collected after tapping. Results are means of 100 (dry cuts) and 10 (sucrose) trees obtained by October of the 4th year of tepping

\begin{tabular}{lccc}
\hline Clone & $\begin{array}{c}\text { Dry cuts } \\
{[\% \text { of total }}\end{array}$ & $\begin{array}{c}\text { Sucrose } \\
{[\mathrm{mM} \text { serum] }}\end{array}$ \\
\hline PB 235 & $21.4^{*}$ & $5.2^{*}$ \\
GT 1 & 9.3 & 10.9 \\
AVROS 2037 & 7.7 & 12.7 \\
RRIM 600 & $6.8^{*}$ & $\mathbf{1 5 . 8 ^ { * }}$ \\
PB 217 & 4.8 & $33.7^{*}$ \\
\hline
\end{tabular}

\footnotetext{
* Significant differences from the clone GT 1. Results on bark dryness are from Annual Report 1982 Rubber Research Institute, Ivory Coast.
} 


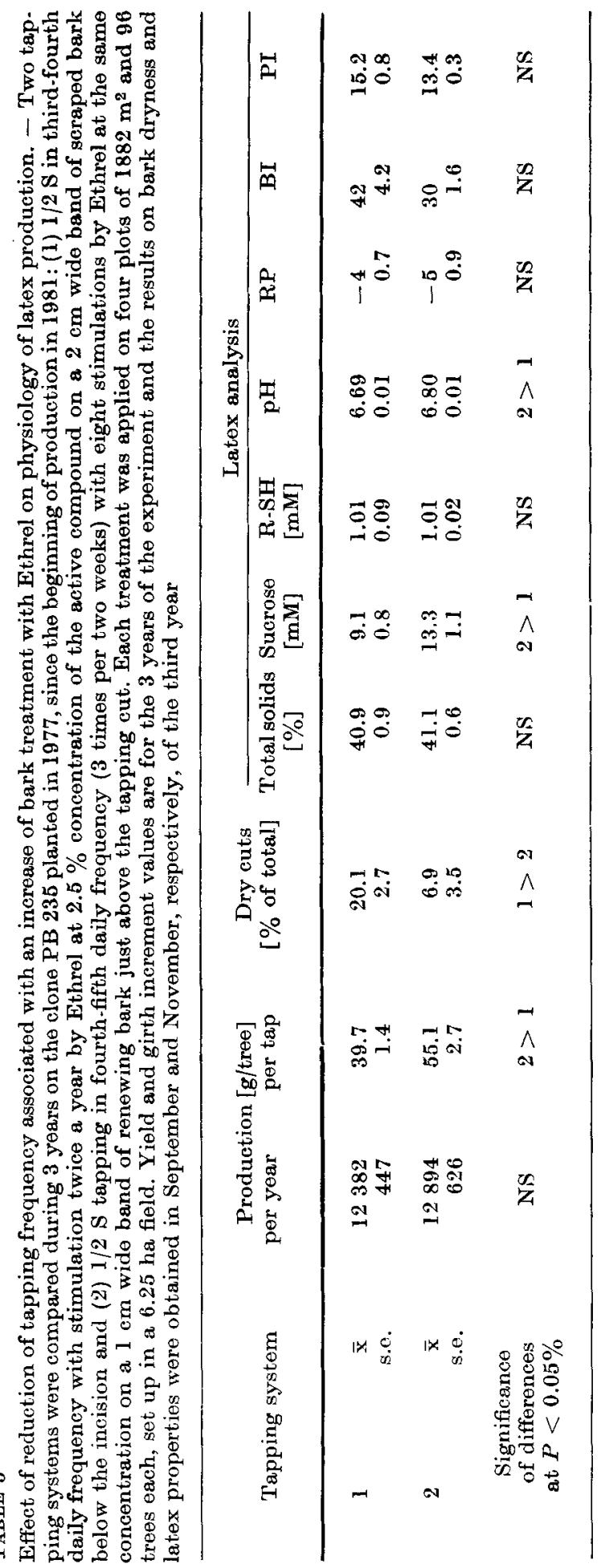


In plant assimilate economy and total productivity, an important role is played by the relationships between sinks and sources influencing translocation, assimilate accumulation in leaves and photosynthetic activity (Wareing and Patrick 1975, Harsen 1978). In the process of conventional tapping, most of the external bark with secondary phloem tissue is removed, the thickness of the remaining layer being only 1 to $2 \mathrm{~mm}$. Although the conducting phloem zone is restricted to a narrow band adjacent to the cambium (HEBANT and DE FAY 1980), bark removal by tapping reduces downward sucrose translocation and the reduction of latex vessel feeding is proportional to the surface of consumed bark above the tapping cut (TUPY 1985). In agreement with this, the present results showed that during 3 years the sucrose level in the latex greatly increased as a result of shortening the tapping cut from full to half-spiral and especially by changing the descending direction of tapping into an ascending one. This was not produced by a decrease in sugar consumption which, on the contrary, was raised, too, as indicated by higher latex yields. Moreover, the increase of production was achieved without a significant alteration of the girth increment which suggests that the improvement of conditions for the photosynthate translocation resulted in strengthening the feedback sink-source mechanism and in an increase of biomass production. Similarly, improvements in photosynthate allocation for latex production could be obtained by manipulating age and hence transport capacity of regenerating bark above the tapping cut.

The appearance of partially or completely nonyielding tapping cuts resulting from physiological disorders produced by tapping (bark dryness or brown bast disease) seems to have various primary or secondary causes under different conditions. The observed association between the incidence of dry cuts and sucrose depletion when comparing either different clones, different intensities of exploitation or seasonal changes, suggested that normally, in the absence of a drastic inducing factor, the cessation of yield may be related to premature senescence of the laticiferous system enhanced by an inadequate sucrose availability for metabolic activities necessary for maintaining normal cellular functions under the given conditions (TuPÝ 1985). This is supported by the present data showing an inverse relation between latex sucrose and the incidence of cut dryness, both in a comparative clonal trial and under different tapping systems. A high frequency of dry cuts appeared even at relatively low latex production under unfavourable conditions for sucrose translocation. A decrease in dry cut incidence in the clone PB 235 when the frequency of tapping was reduced did not result from a lowering of latex output which rather tended to increase. It suggests that in this clone, exhibiting high depletion of latex sucrose at normal tapping conditions, an extension of time intervals between two tappings is required for renewal of cell structures and normal functions including the transport systems requiring metabolic energy.

Under different environmental, clonal and tapping conditions, a correlation of latex yield with different latex characteristics can be found within trees of the same field and treatment (EscнвасH et al. 1984). The analysis of these characteristics, such as total solid content, sucrose, thiols, $\mathrm{Mg}^{2+}, \mathrm{Pi}, \mathrm{pH}$, redox potential, bursting index of lutoids and plugging index of latex flow, indicated that the improvement of saccharides feeding can be considered as a major factor of latex vessel productivity. 


\section{REFERENCES}

Archer, B. L., Barnard, D., Cockbain, E. G., Dickenson, P. B., McMulien; A. I.: Structure, composition and biochemistry of Hevea latex. - In: Bateman, L. (ed.): The Chemistry and Physics of Rubber-like Substances. Pp. 41-72. Maclaren, London 1963.

Bealing, F. J., Chua, S. E.: Output, composition and metabolic activity of Hevea latex in relation to tapping intensity and the onset of brown bast. - J. Rubb. Res. Inst. Malaya 23 : $204-231,1972$.

Chong, F. C.: The role of carbohydrates in the exploitation and latex flow of Hevea. - Thesis summary, Univ. Ghent, Belgium. J. Rubb. Res. Inst. Malaysia 29 : 125-126, 1981.

Dickenson, P. B.: The ultrastructure of the latex vessels of Hevea brasiliensis. - In: Muluins, L. (ed.): The Proceedings of the Natural Rubber Procedures Research Association Jubilee Conference, Cambridge 1964. Pp. 52-66. Maclaren, London 1965.

Eschbach, J.-M., Rousser, D., VAN DE SYPE, H., JACOB, J.-L., D'AUZAC, J.: Relationships between yield and clonal physiological characteristics of latex from Hevea brasiliensis. Physiol. vég. 22 : 295-304, 1984.

HANSEN, G. K.: Utilization of photosynthates for growth, respiration, and storage in tops and roots of Lolium multiflorum. - Physiol. Plant. 42 : 5-13, 1978.

Hebant, C., De Fay, F.: Functional organization of the bark of Hevea brasiliensis (rubber tree): A structural and histoenzymological study. - Z. Pflanzenphysiol, 97 :391-398, 1980.

Low, F. C.: Distribution and concentration of major soluble carbohydrates in Hevea latex, the effects of Ethephon stimulation and the possible role of these carbohydrates in latex flow. J. Rubb. Res. Inst. Malaysia $26: 21-32,1978$.

Low, F. C., Gomez, J. B.: Carbohydrate status of exploited Hevea J: The effect of different exploitation systems on the concentration of the major soluble carbohydrates in latex. - J. Rubb. Res. Inst. Malaysia $30: 1-18,1982$.

Templeton, J. K.: Partition of assimilates. - J. Rubb. Res. Inst. Malaya 21 : 259-263, 1969.

TUPÝ, J.: Stimulatory effects of 2,4-dichlorophenoxyacetic acid and of l-naphthylacetic acid on sucrose level, invertase activity and sucrose utilization in the latex of Hevea brasiliensis. Planta $88: 144-153,1969$.

TUPצ́, J.: Influence de la stimulation hormonale de la production sur la teneur en saccharose du latex d'Hevea brasiliensis. - Rev. gén. Caout. Plast. 50 : 311-314, 1973a.

TUPÝ, J.: The activity of latex invertase and latex production in Hevea brasiliensis MC̈LL. ARG. Physiol. vég. $11: 633-641,1973 \mathrm{~b}$.

TUPÝ, J.: Some aspects of sucrose transport and utilization in latex producing bark of Hevea brasiliensis Muer. ARg. - Biol. Plent. 27 : 51-64, 1985.

Tup'́, J., Resing, W. L.: Anaerobic respiration in latex of Hevea brasiliensis substrate and limiting factors. - Biol. Plant. $10: 72 \rightarrow 80,1968$.

Warking, P. F., Patrick, J.: Source-sink relations and the partition of assimilates in the plant - In: Cooper, J. P. (ed.): Photosynthesis and Productivity in Different Environments. Pp. 481-499. Cambridge Univ. Press, Cambridge-London-New York-Melbourne 1975. 